\title{
J.D. Livingston
}

\section{Sixteen New Metals}

Whatever your specialty is in materials science, imagine how many years of new experiments you could plan if you suddenly learned that 16 new elements had been discovered. Materials scientists found themselves in a similar situation after World War II (even though they did not yet call themselves "materials scientists"). In their preface to the 1961 symposium report ${ }^{1}$ entitled The Rare Earths, editors F.H. Spedding and A.H. Daane wrote the following:

"The availability in large volume of 16 new metals with rather distinctive new properties brought this book into being. We refer to the so-called rare earths and associated elements lanthanum, yttrium, and scandium, which total about one-fourth of our known metals. Here is a practically untapped source of unique metals. Elements such as cerium, lanthanum, neodymium, and yttrium are as abundant as lead and tin, and even the least common rare earths are more abundant than the platinumgroup metals and gold."

Basic materials research in the 1950s and 1960 s on these newly available metals led to the development of three generations of rare-earth magnets in the 1970 s and 1980s. These magnets have found important application in a wide range of products, including motors and earphones, computers and printers, antilock brake systems, and magnetic-resonance imaging.

The "so-called rare earths" ("socalled" because they are neither rare nor earths) referred to by Spedding and Daane are elements 58 through 71, the 14 $4 f$ elements (of which only 13 are stable, prometheum being radioactive). Although most of these and the three chemically similar "associated" elements ( $\mathrm{La}, \mathrm{Y}$, and $\mathrm{Sc}$ ) were discovered in the nineteenth century, they were very difficult to separate. Prior to World War II, only a few were available in quantity, and they were not of high purity. However one happy by-product of the Manhattan Project was improved separation methods for these elements. These methods were commercialized soon after the war, making these "16 new metals" available in large quantities and high purity.
As used today, the term "rare earths" commonly includes the $4 f$ elements plus La, Y, and, less frequently, Sc. The rare earths were of interest to the Manhattan Project largely because they were common fission products of uranium. Although these metals retain some applications in the nuclear industry, materials research in the 1950s and 1960s led to many other applications, the most notable of which being permanent magnets much more powerful than any previously known.

\section{Early Magnetic Studies}

It was realized early that one of the most interesting physical properties of rare-earth metals was their high magnetic moments, resulting from unpaired $4 f$ electrons. Two rare earths-Dy and Ho-have the highest magnetic moment per unit volume of all the elements, more than $50 \%$ higher than that of iron. They and five other rare earths are ferromagnetic. That's the good news. The bad news is that their Curie temperatures are well below room temperature (except Gd, for which $T_{\mathrm{c}}=293 \mathrm{~K}$, making it weakly ferromagnetic in a sufficiently cool room). Curie temperatures are low because the $4 f$ electrons are relatively close to the nucleus, shielded by outer electrons, and overlap little with the $4 f$ electrons of neighboring atoms. Interatomic exchange forces that produce ferromagnetism in the rare earths are much weaker than in the $3 d$ ferromagnetic metals $\mathrm{Co}, \mathrm{Fe}$, and $\mathrm{Ni}$.

Could alloying the rare earths with these $3 d$ transition metals combine the high magnetic moments of the rare earths with the high Curie temperatures of $\mathrm{Co}$, $\mathrm{Fe}$, and Ni? Among the early groups exploring $3 d-4 f$ alloys were Nesbitt et al. ${ }^{2}$ (Bell Telephone Laboratories), Nassau et al. ${ }^{3}$ (University of Pittsburgh), and Hubbard et al. ${ }^{4}$ (U.S. Naval Research Laboratories [NRL]). (Industrial, university, and government labs were all active

Links of Science and Technology describes the origin, science, technology, and unique accomplishments of advances in materials science that have had significant practical value. in this early stage of research.) The NRL group reported two interesting features concerning the magnetic properties of the compound $\mathrm{GdCO}_{5}$. First, after grinding to powder, it had a coercivity (the reverse field required to reduce the net magnetization to zero - that is, to demagnetize it) of over $8,000 \mathrm{Oe}(0.8 \mathrm{~T})$. Second it required a magnetic field of over $30,000 \mathrm{Oe}(3 \mathrm{~T})$ to saturate the magnetization - that is, to align all the atomic magnetic moments. This indicated that the compound had a very high magnetic anisotropy. At this point, some brief reminders about ferromagnetic properties may be in order.

In ferromagnetic crystals, certain directions are the preferred (easy) directions of magnetization. The energy difference per unit volume between a crystal magnetized in an easy direction and the same crystal magnetized in a high-energy (hard) direction is termed its magnetic anisotropy. With a polycrystalline sample or with a single-crystal sample with the field applied along a hard axis, a substantial field may be necessary to rotate all the atomic magnets out of the easy axes and into the direction of the field, that is, to saturate the magnetization. This field is a measure of the magnetic anisotropy of the material.

A good permanent magnet should not only be very magnetic (have a high saturation magnetization at room temperature) but also be very permanent (have a high coercivity - be difficult to demagnetize). By the 1960 s, it was widely known that materials with high magnetic anisotropy of "easy axis" symmetry (only one preferred direction of magnetization) had the potential for high coercivity. The prime example was the hexagonal ferrites, introduced in the 1950 s, but other examples included several intermetallic compounds - tetragonal CoPt and $\mathrm{MnAl}$, and hexagonal $\mathrm{MnBi}$.

For the small group of workers searching for improved permanent-magnet materials, the guidelines became (1) high saturation magnetization, (2) high Curie temperature (well above room temperature), and (3) high easy-axis magnetic anisotropy (usually associated with hexagonal, tetragonal, or other noncubic crystal structures). The results of Hub- 
bard et al. ${ }^{4}$ showed that the hexagonal compound $\mathrm{GdCo}_{5}$ met the second and third criteria but did not meet the first because the $\mathrm{Gd}$ and $\mathrm{Co}$ moments were coupled antiparallel, reducing the net magnetization of the compound. (The same was found to be true for compounds of Dy and Ho with Co, dashing original hopes to combine the high moments of the heavy rare earths with the high Curie temperatures of the $3 d$ metals.) However in 1966, Hoffer and Strnat ${ }^{5}$ reported that the corresponding compound of Co with nonmagnetic $\mathrm{Y}$, $\mathrm{YCO}_{5}$, met all three criteria and therefore had the potential to become a superior permanent-magnet material. The door had been opened for the development of the first generation of rare-earth magnets.

\section{Rare-Earth-Cobalt Magnets}

Magnetic measurements on powders of several $\mathrm{RCO}_{5}$ and $\mathrm{R}_{2}(\mathrm{Co}, \mathrm{Fe})_{17} \mathrm{com}$ pounds $^{6-8}(\mathrm{R}=$ rare earth) soon showed that several of these compounds with light rare earths had promising values of magnetization, Curie temperature, and anisotropy. So far, so good. However although these are necessary conditions for good permanent magnets, they are not sufficient. High magnetic anisotropy shows the potential for high coercivity, but coercivity is a highly structuresensitive property, usually best achieved in a finely divided material. To utilize the full value of a high saturation magnetization, it is necessary to develop a processing method that produces a dense material with the magnetic easy axes aligned. Otherwise the remanent magnetization (the magnetization remaining after a magnetizing field is removed) is far less than the saturation magnetization. It required several years before $\operatorname{Das}^{9}$ (Raytheon) and Benz and Martin ${ }^{10}$ (General Electric [GE]) were able to produce dense, aligned, highcoercivity $\mathrm{SmCO}_{5}$ magnets by sintering magnetically aligned powder (a process similar in principle to the one used to produce aligned ferrite magnets, but made more difficult by the reactivity of $\mathrm{Sm}$ and complexities of the Sm-Co phase diagram).

General Electric was the first to commercialize rare-earth magnets in the form of bulk sintered $\mathrm{SmCo}_{5}$ but soon sold its magnet business, including all the pertinent patents, to Hitachi. General Electric management saw this as an opportunity to sell off a business that had been relatively unprofitable in the past, rather than as an opportunity for future profits. Technological leadership in rareearth magnets moved to Japan.
The single quality measure most commonly used by engineers to evaluate permanent magnets is maximum energy product, a quantity that depends on both remanent magnetization and coercivity. The higher the energy product, the less magnet is needed for a specific application. The magnets dominant before 1970 were the ferrites and alnicos and the first $\mathrm{SmCo}_{5}$ magnets had energy products more than twice the energy product of the alnicos, and more than five times the energy product of the ferrites. They had magnetizations much higher than the ferrites and coercivities much higher than the alnicos. For some applications these were more important quality criteria than energy product. Nevertheless the relatively high cost of $\mathrm{SmCo}_{5}$ magnets first limited them to military and space applications where cost was much less important than performance and to commercial applications like wrist watches and earphones where the amount of magnet used in each device was very small.
To increase awareness of the wide engineering potential of these remarkably powerful new magnets, Karl Strnat of the University of Dayton, known widely as "the father of rare-earth magnets," instituted in 1974 a series of workshops on "Rare Earth Permanent Magnets and Applications" that continues to this day. The most effective use of rare-earth magnets often involves not simple substitution of the new magnets into old designs but entirely new designs. These workshops helped shorten the transition from scientific discovery to industrial applications and prepared the ground for rapid utilization of other classes of rareearth magnets that were developed later.

This "first generation" of rare-earth magnets based on $\mathrm{RCO}_{5}$ compounds was followed about six years later by a second generation based on $\mathrm{R}_{2}(\mathrm{Co}, \mathrm{Fe})_{17} \mathrm{com}-$ pounds, which have higher magnetizations. These compounds exist in both hexagonal and rhombohedral modifications, but only a few have the desired "easy-axis" anisotropy, and anisotropies

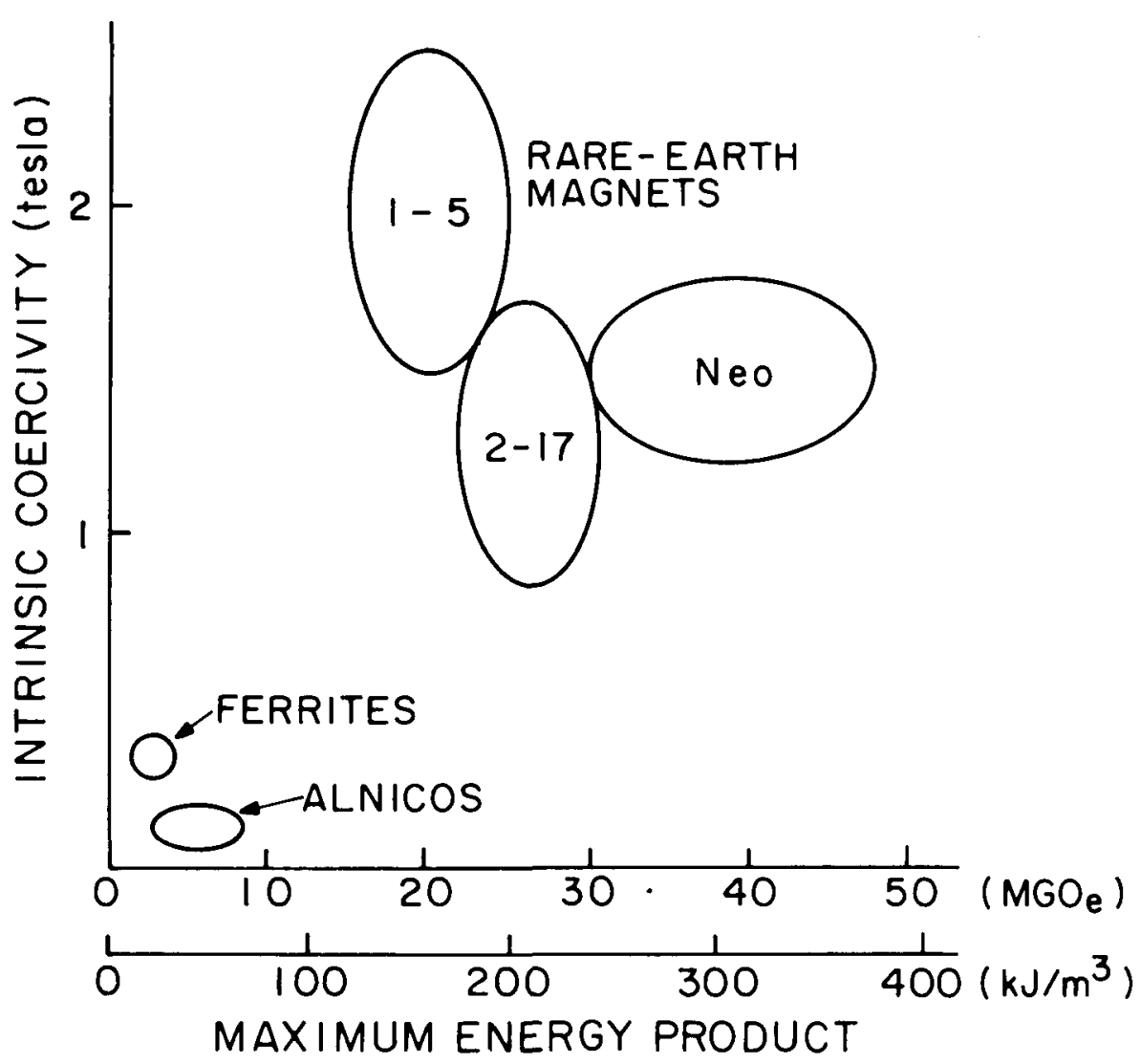

Figure 1. Schematic representation of property ranges of three generations of dense, aligned rare-earth magnets (1-5, 2-17, and neo magnets) in comparison to ferrite and alnico magnets. Energy products are lower for unaligned magnets and bonded magnets (powdered magnets in nonmagnetic matrices). 
were generally lower than those of the $\mathrm{RCO}_{5}$ compounds. The most successful "2-17" magnets were based on $\mathrm{Sm}_{2} \mathrm{Co}_{17}$ with additions of $\mathrm{Cu}, \mathrm{Fe}$, and $\mathrm{Zr}$, and fine two-phase microstructures produced by coherent precipitation. Although coercivities were lower than those of $\mathrm{SmCo}_{5}$ ("1-5") magnets, magnetizations were higher, leading to higher energy products. In many cases the lower coercivities (still much higher than those of ferrites and alnicos) were an advantage since the high coercivities of $\mathrm{SmCO}_{5}$ magnets (approaching or exceeding 2 T) made them difficult to magnetize. But cost was still a problem, and political upheavals in Africa in 1978 suddenly drove up the price of cobalt by more than a factor of five. Development of cobalt-free permanent magnets became a high priority, setting the stage for the entrance of the third and most exciting (so far) generation of rare-earth magnets, those based on $\mathrm{Nd}_{2} \mathrm{Fe}_{14} \mathrm{~B}$.

\section{"Neo" Magnets}

Even without the supply problems of the late $1970 \mathrm{~s}$, cobalt was and remains much more expensive than iron. Why were the first two generations of rareearth magnets based on compounds with cobalt? Early research on these "16 new metals" was focused on binary compounds, which was quite enough challenge at first since there are more than a thousand stable binary rare-earth compounds, including over $200 \mathrm{com}$ pounds with $\mathrm{Co}, \mathrm{Fe}$, or $\mathrm{Ni} .{ }^{11}$ The stable binary $\mathrm{R}-\mathrm{Fe}$ compounds just were not as promising as the R-Co compounds. Either the magnetizations were low (like the $\mathrm{RFe}_{2}$ and $\mathrm{RFe}_{3}$ compounds), the Curie temperatures were low (the $\mathrm{R}_{2} \mathrm{Fe}_{17}$ compounds), or they weren't even stable $\left(\mathrm{RFe}_{5}\right)$. The third generation of the rareearth magnets is based on a ternary rareearth compound.

Russian scientists have long been active in rare-earth research, and ternary phase diagrams have been a specialty of Russian metallurgists. It is therefore not surprising that the stable tetragonal compound $\mathrm{Nd}_{2} \mathrm{Fe}_{14} \mathrm{~B}$ was first reported in a 1979 Russian publication on the Nd-Fe-B phase diagram. ${ }^{12}$ However, this group apparently made no attempt to determine the magnetic properties of this newly discovered compound. Four years passed before Sumitomo ${ }^{1.3}$ and General Motors (GM) $)^{14}$ announced new permanent magnets based on $\mathrm{Nd}_{2} \mathrm{Fe}_{14} \mathrm{~B}$. The Sumitomo magnets were made by sintering of magnetically aligned powder, a process similar to that used for $\mathrm{SmCO}_{5}$ magnets. However, the GM magnets

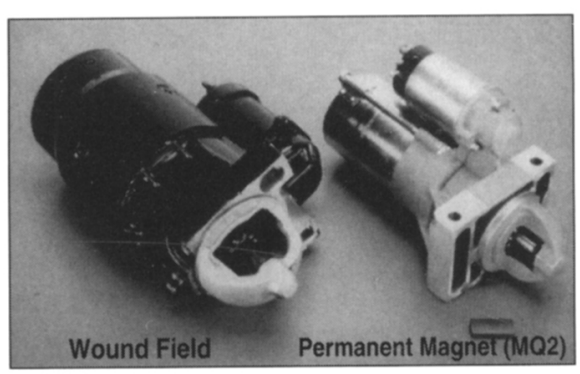

Figure 2. Showing the reduction in size of General Motors starting motors resulting from the use of neo magnets. (Magnaquench 2 is a dense unaligned magnet produced by pressing of rapidly solidified alloy.)

were made by a process that by then was drawing considerable interest in several areas of materials science-rapid solidification by melt-spinning.

Among those working on magnetic materials, most research in rapid solidification (RS) in the 1970s was aimed at soft magnetic materials-low-coercivity amorphous metals for ac applications like transformers. However RS processing followed by crystallization anneals at low temperatures had also become recognized as a process for producing uniquely fine-scaled microstructures and for producing metastable phases. In 1973 Clark of the Naval Ordnance Lab reported ${ }^{15}$ that $\mathrm{RS} \mathrm{TbFe}_{2}$, after a subsequent crystallization anneal, had a coercivity greater than $0.3 \mathrm{~T}$ and an energy product greater than that of the ferrites. (The Laves phase $\mathrm{TbFe}_{2}$ had a huge magnetic anisotropy even though it was cubic in symmetry and therefore had several equivalent "easy axes.") Although most magnet specialists were focusing on R-Co in 1973, a few years later interest in cobalt-free magnets, and in Clark's results, heated up. Among those looking at RS alloys containing rare earths and iron were Croat of GM and Koon and Das of the Naval Research Labs. Croat ${ }^{16}$ reported high coercivities in Pr-Fe and Nd-Fe, and Koon and Das ${ }^{17}$ in R-Fe-B. (Boron was a "glass-forming" element commonly included in RS alloys.)

From the early work of Hubbard et al. to the later work by Clark and co-workers, and by Koon and Das, Navy laboratories had made important contributions to developments in this field. Motivated by this history, and by the price and supply problems with cobalt, the Office of Naval Research (ONR) also began funding external research on cobalt-free magnets at several labs, including RS work by Hadjipanayis and co-workers, ${ }^{18}$ who reported promising properties in Pr-Fe-B-Si. Polk of ONR organized a session on "Fe-Based Microcrystalline Permanent Magnet Alloys" at a magnetism conference held in Pittsburgh in November 1983, at which various groups reported on their research, and GM and Sumitomo described their commercial $\mathrm{Nd}-\mathrm{Fe}-\mathrm{B}$ magnets. Although GM's RS magnets had grain sizes 100 times finer than the grain sizes of Sumitomo's sintered magnets, both were based on the same stable $\mathrm{Nd}_{2} \mathrm{Fe}_{14} \mathrm{~B}$ compound. The initial RS magnets were unaligned, with lower remanent magnetizations and energy products than the aligned sintered magnets. However high-temperature deformation of the RS material was later introduced to produce substantial alignment of the magnetic easy axes and increased energy products.

As a result of higher magnetizations, neo magnets have higher energy products than the first two generations of rare-earth magnets. Representative property ranges for dense and aligned rareearth magnets, and for ferrites and alnicos, are shown in Figure 1. Even more important, these improved properties were accompanied by lower rawmaterials cost. With cobalt replaced by much cheaper and more plentiful iron, and samarium replaced by cheaper and more plentiful neodymium, the aptlynicknamed "neo" magnets rapidly expanded engineering interest in, and applications of, rare-earth magnets. Before turning to those applications, it might be appropriate, for a series devoted to links between science and technology, to briefly note our indebtedness to nineteenth-century science.

\section{The New Twin}

The building blocks used by materials scientists are the hundred-odd elements of the periodic table. Like musicians with their notes and painters with their colors, materials scientists experiment with new combinations and arrangements of this finite set of chemical elements. Although the development of rare-earth magnets can be traced back to basic research on rare-earth metals and compounds that began in earnest after World War II, it is worth remembering that 20 th-century materials science is built upon the efforts of scientists of earlier centuries who separated and identified the various elements, a task that was especially difficult for the chemically similar rare earths. ${ }^{19}$

In Stockholm in 1843, Carl Gustaf Mosander reported the separation of 
cerium minerals into cerium oxide, lanthanum oxide, and a third oxide he called didy mium oxide (from didymos, Greek for twin, because it accompanied cerium and lanthanum as a "twin" in those minerals). He suggested the symbol $D$ for didymium, which for over 40 years was believed to be an element. However it was very aptly named because in 1885 didymium was further separated into two elements, originally named praseodidymium (green twin) and neodidymium (new twin). The chemist who separated didymium was Carl Auer von Welsbach, who formerly was pictured on the Austrian 20-shilling note (surely one of the few chemists whose likeness ever achieved such wide circulation). Within a few years, the names of the two hard-to-separate elements had been simplified to praseodymium and neodymium. A century later, magnets based on a ternary neodymium compound would revolutionize electromagnetic technology.

\section{Using Neo Magnets}

You have probably seen the now-common demonstration of a neo magnet levitating above a "high temperature" superconductor immersed in liquid nitrogen. The superconductor, discovered in 1987, received intense media coverage and has generated, to date, over a billion dollars of research funding from U.S. government agencies alone. The neo magnet, discovered in 1983, has in comparison been virtually ignored by the media and funding agencies. Yet the high temperature superconductor has few applications today and is unlikely ever to become nearly as important to technology as the neo magnet, which already has hundreds of important applications.

Few are aware of how many hidden permanent magnets are providing the forces that operate devices we use every day in our homes, cars, offices, and factories. By converting electrical energy into kinetic energy in motors and into sound energy in speakers, magnets are literally the "movers and shakers" of modern technology. Where performance is the dominant criterion, as in computer disk drives, printers, and miniature earphones, it is increasingly neo magnets that are doing the moving and shaking.

Two decades of experience with R-Co magnets taught mechanical and electrical engineers how to best utilize the advantages of high-coercivity and highenergy product materials. Thus the ground was well prepared for the advent of neo magnets, which offer even higher

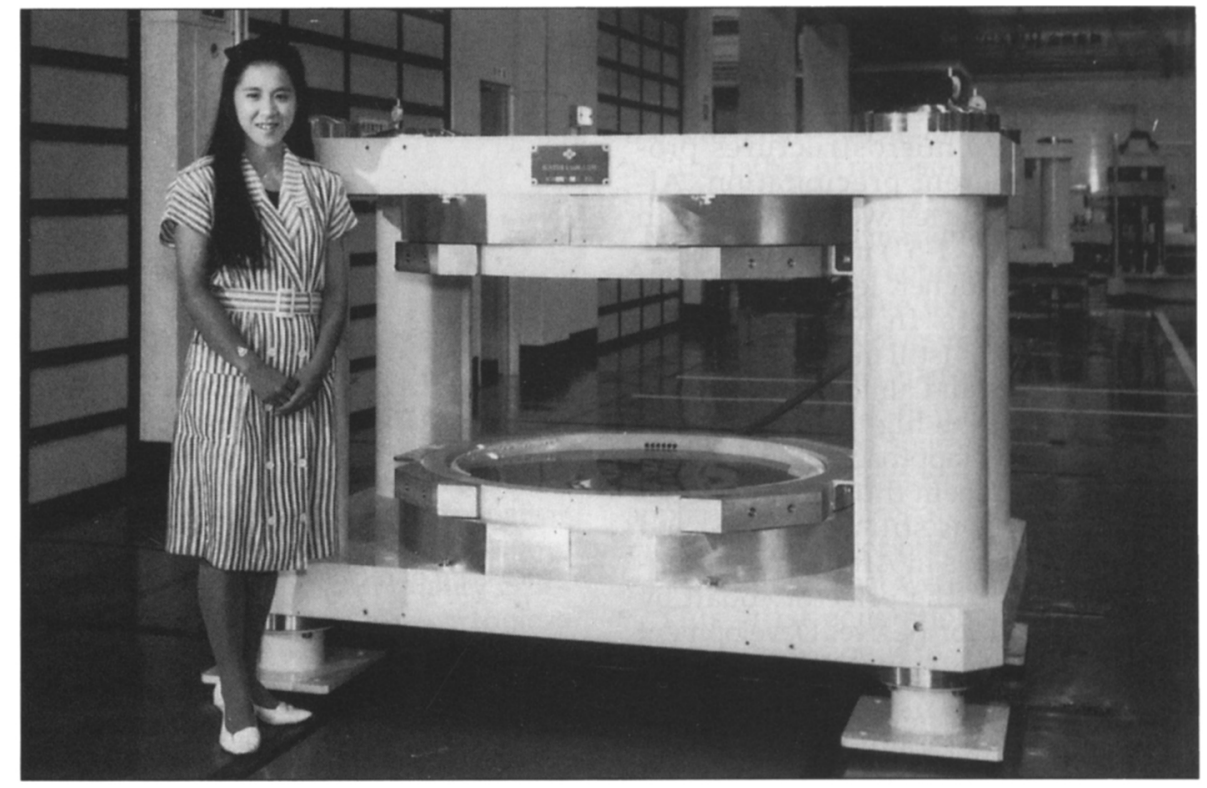

Figure 3. Permanent-magnet magnetic-resonance-imaging system produced by Sumitomo. Large disks of neo magnets at the top and bottom produce a vertical magnetic field in the gap of $0.2 T$. The steel support structure withstands magnetic forces and provides a return path for the flux.

energy products at lower cost. Although ferrite magnets are still much cheaper and remain the choice where cost is the overwhelming criterion, neo magnets have energy products that are higher by an order of magnitude, allowing motors, speakers, and other electromechanical devices to do the same job with far less magnet. This results not only in reductions in size and weight of the device (as in GM starting motors, see Figure 2), but also increased design options, such as efficient disk motors, stepper motors, and brushless motors with permanentmagnet rotors. With increasing energy products, permanent magnets can replace electromagnets in larger and larger electric motors, and compact lightweight motors over 1,000 kilowatts in power ( 750 horsepower) have been successfully constructed using neo magnets. Without rare-earth magnets, motors of the same power rating would be at least five times heavier and would be less efficient because of resistive energy losses in the electromagnet windings.

Neo magnets are also becoming widely used in sensors, as in aircraft flight controls, combustion engines, and antilock brake systems, where very small magnets are sufficient for the job. Magnets can be used to sense position, force, torque, speed, acceleration (e.g., in airbag sensors) and, of course, current and magnetic field. The motors and actuators that respond to sensor signals also usually employ magnets, and smaller magnets mean less inertia and more rapid response. Rare-earth magnets have become, in the words of the late magnet expert R.J. Parker, "the companion components to microelectronics in changing the speed of doing things."

At the other end of the size spectrum, Sumitomo has designed a magneticresonance-imaging (MRI) system that uses over two tons of Nd-Fe-B (Figure 3). With over a thousand such systems already delivered, this application accounts for a substantial fraction of the total tonnage of neo magnets produced today. But even for such a system, the major advantage of neo magnets over ferrites is that their superior properties allow the use of less magnet for the same application. For a design field of $0.2 \mathrm{~T}$, an MRI system that would require 21 tons of ferrites and a total system weight of 70 tons uses 2.6 tons of neo magnets and a total system weight of 24 tons. (Most of the system weight is in the steel structure that withstands the huge magnetic forces and provides a return path for the flux.)

In 1960 the total market for soft magnetic materials (largely steels for transformers, motors, and generators) was about six times the total market for per- 
manent-magnet (hard) magnetic materials. Although the market for soft magnetic materials has nearly quadrupled since then, the market for hard magnetic materials now surpasses it and is currently expanding at a rate of nearly $15 \%$ per year. Although the market for ferrites continues to grow, the fastest growing part of the market for permanent magnets today is that for neo magnets. Japan is the leading producer, and China is in second place. With about $80 \%$ of the world's known reserves of rare earths, and with the recent purchase of GM's neo magnet business ("Magnaquench") by a Chinese group, China is clearly positioned to be a major player in the future of permanent magnets.

\section{Science to Technology}

The element neodymium was discovered a little over a century ago, and became available in quantity and high purity, along with other rare earths, only about 50 years ago as a result of a wartime program to develop the atom ic bomb. Thus a very expensive, high-priority applied research and development program provided an important spin-off for basic research. Although much of the materials research on these " 16 new metals" in the 1950s and 1960s could be characterized as basic research, largely motivated by scientific curiosity, some workers soon realized a possible potential for improved magnetic materials. However, several years of focused research were required to gather data on basic magnetic properties (magnetization, Curie temperature, magnetic anisotropy) on many binary rare-earth compounds before a few promising compounds were identified, and then many months of process development were required before the first commercial rareearth magnets reached the market.

After nearly a decade of applied research and development focused on improving R-Co magnets, attention shifted to R-Fe-based alloys, leading in about five years to the development of a third generation of rare-earth magnets, neo magnets, based on a ternary R-Fe-B compound. Remarkably, two very different processing approaches converged on the same ternary compound. One approach was based on traditional sintering of powders, the other on rapid solidification, a processing technique widely studied by materials scientists in the 1970s. Neo magnets gained rapid market acceptance largely because earlier but more expensive rare-earth magnets had given engineers design experience that could easily be extended to the new materials. The last dozen years have seen much applied R\&D aimed at alloying additions and processing modifications to overcome some of the limitations of neo magnets, for example, low Curie temperatures and poor corrosion resistance.

\section{Few are aware of how many hidden permanent magnets provide forces that operate devices we use every day in our homes, cars, offices, and factories.}

More general materials research continues with the search for still better materials among the thousands of possible ternary and higher order compounds, both stable and unstable. Most effort is focused on $\mathrm{R}-\mathrm{Fe}-\mathrm{X}$ compositions, with $X$ mostly metalloids and/or transition metals. Among other compositions, $\mathrm{Sm}-\mathrm{Fe}-\mathrm{N}$ and $\mathrm{Sm}-\mathrm{Fe}-\mathrm{Ti}$ alloys with promising properties have been uncovered but appear unlikely to outdo neo magnets. Basic calculations suggest that still higher energy products are possible, but a compound with the right combination of properties must first be found, followed by development of practical processing techniques. In the first three generations of rare-earth magnets, the $3 d$ elements largely contributed the exchange interactions that produced Curie temperatures above room temperature, and the $4 f$ elements contributed, instead of the huge magnetic moments originally hoped for, the magnetic anisotropies that provided the potential for high coercivity. Although information about magnetic moments, exchange forces, and magnetic anisotropies of $3 d$ and $4 f$ elements in various crystal structures has grown substantially over the years, much remains incompletely understood. Discovery of the composition and processing approach that will eventually produce a new material to surpass $\mathrm{Nd}_{2} \mathrm{Fe}_{14} \mathrm{~B}$ magnets will probably depend at least as much upon empiricism and serendipity as upon our basic understanding of the fascinating but complex phenomena of ferromagnetism.

\section{References}

1. F.H. Spedding and A.H. Daane, eds., The Rare Earths (John Wiley \& Sons, New York, 1961).

2. E.A. Nesbitt, J.H. Wernick, and E. Corenzwit, J. Appl. Phys. 30 (1959) p. 365.

3. K. Nassau, L.V. Cherry, and W.E. Wallace, J. Phys. Chem. Solids 16 (1960) p. 131.

4. W.M. Hubbard, E. Adams, and J.V. Gilfrich, J. Appl. Phys. 31 (1960) p. 3685.

5. G. Hoffer and K. Strnat, IEEE Trans. Magn. MAG-2 (1966) p. 487; J. Appl. Phys. 38 (1967) p. 1378.

6. K. Strnat, G. Hoffer, J. Olson, W. Ostertag, and J.J. Becker, ibid. 38 (1967) p. 1001.

7. A.E. Ray and K.J. Strnat, IEEE Trans. Magn. MAG-8 (1972) p. 516.

8. H.G. Schaller, R.S. Craig, and W.E. Wallace, J. Appl. Phys. 43 (1972) p. 3161.

9. D.K. Das, IEEE Trans. Magn. MAG-5 (1969) p. 214.

10. M.G. Benz and D.L. Martin, Appl. Phys. Lett. 17 (1970) p. 176

11. K.H.G. Puschow, in Ferromagnetic Materials, vol. 1, edited by E.P. Wohlfarth (NorthHolland, Amsterdam, 1980) p. 297.

12. N.F. Chaban, Yu.B. Kuz'ma, N.S. Bilonizhko, O.O. Kachmar, and N.V. Petrov, Izv. Akad. Nauk Az. SSR Ser. Fiz.-Tekh. \& Mat. Nauk 10 (1979) p. 873.

13. M. Sagawa, S. Fujimura, M. Togawa, and Y. Matsuura, J. Appl. Phys. 55 (1984) p. 2083.

14. J.J. Croat, J.F. Herbst, R.W. Lee, and F.E. Pinkerton, ibid. p. 2078.

15. A.E. Clark, Appl. Phys. Lett. 23 (1973) p. 642 .

16. J.J. Croat, J. Appl. Phys. 53 (1982) p. 6932; IEEE Trans. Magn. MAG-18 (1982) p. 1442.

17. N.C. Koon and B.N. Das, Appl, Phys, Lett. 39 (1981) p. 840.

18. G.C. Hadjipanayis, R.C. Hazelton, and K.R. Lawless, ibid. 43 (1983) p. 797.

19. F. Szabadvary, in Handbook on the Physics and Chemistry of Rare Earths, vol. 11, edited by K.A. Gschneidner, Jr. and L. Eyring (NorthHolland, Amsterdam, 1988) p. 33.

20. R.J. Parker, Advances in Permanent Magnetism (Wiley \& Sons, New York, 1990).

James D. Livingston received his PhD degree from Harvard University in applied physics. From 1956 to 1989, he was a physicist with General Electric Corporate Research and Development in Schenectady, New York, where he studied the magnetic, superconducting, and mechanical properties of metals and alloys. Currently a senior lecturer in the Department of Materials Science and Engineering at the Massachusetts Institute of Technology, he has recently completed a popular-science book on the history, legends, science, and technology of magnets, entitled Driving Force: The Natural Magic of Magnets, published by Harvard University Press. Livingston can be reached at the Massachusetts Institute of Technology, Room 13-4066, 77 Massachusetts Avenue, Cambridge, MA 02139; phone 617-253-0059; fax 617-258-8539; e-mail jdliv@mit.edu. 